\title{
Splenic Morphometry in a Group of Sri Lankan Adult Population
}

\section{- A Preliminary Cadaveric Study}

\section{S. K. Y. I. KODIKARA ${ }^{1}$, B.C. I. J. NANAYAKKARA ${ }^{2}$, B. G. NANAYAKKARA ${ }^{1}$, I. ILAYPERUMA ${ }^{1}$}

\begin{abstract}
Introduction: A detailed knowledge on morphometric variations of the spleen is of great value in diagnosing splenomegaly clinically, radiologically and for surgical procedures.

Objectives: This study was undertaken to establish splenic morphometry in a group of Sri Lankan adults.

Methodology: Splenic morphology was noted and maximum length, thickness, width were recorded $(n=30)$ using a vernier caliper (Tricebrand) with minimum measurement of $0.001 \mathrm{~cm}$. The weight was measured with a manual triple beam balance (up to $0.1 \mathrm{~g}$ ). Splenic index (width $\mathrm{x}$ length $\mathrm{x}$ thickness) and splenic volume (0.524 x splenic index) were calculated. Cadavers with history of haemopoetic or reticular endothelial disorders, ruptured, grossly adhered spleens were excluded from the study. Results were expressed as mean \pm SD. Results: Out of the total spleens, $43.3 \%$ were semilunar, $33.3 \%$ wedge, $10 \%$ oval, $3.3 \%$ tetrahedral, 6.6\% polygonal wedge shaped and 3.3\% single lobed liver shaped. Notches were absent in $16.67 \%$ and when notches are present they are exclusively in the superior border. Single notch was present in $26.7 \%$. Out of single notches, $30 \%$ were posterior pole notches. More than one notch was present in $46.7 \%$ and the $81.8 \%$ of those were in the anterior pole. Mean length, width and thickness were $8.06 \mathrm{~cm} \pm 1.66,7.65 \mathrm{~cm} \pm 1.05$ and $5.33 \mathrm{~cm} \pm 0.89$ respectively. Splenic index was 174.67. Splenic volume and weight were $91.52 \mathrm{~cm}^{3}$ and $80.13 \mathrm{~g} \pm 35.84$ respectively.
\end{abstract}

Conclusion: This pilot study reveals that the splenic morphology is in par with other populations and bipolar length of the spleen has strong positive correlation with the volume. Large scale study is recommended to establish population specific data base.

Key words: spleen, morphometry 
KODIKARA S. K. Y. I., NANAYAKKARA B.C. I. J, NANAYAKKARA B. G., ILAYPERUMA I. Splenic Morphometry in a Group of Sri Lankan Adult Population-A Preliminary Cadaveric Study. Sri Lanka Anatomy Journal (SLAJ), 1(1): 44-52, 2017.

\section{INTRODUCTION}

Spleen is the largest lymphoid organ of the body, found in the left upper quadrant of the abdomen beneath the diaphragm, adjacent to $9^{\text {th }}, 10^{\text {th }}$ and $11^{\text {th }}$ ribs, oriented along the long axis of the $10^{\text {th }}$ rib (1). William's et al. described the spleens wedge to tetrahedral in shape with two surfaces; diaphragmatic and visceral. There are two borders; superior, inferior and anterior, posterior extremities. Upper and lower poles are described as posterior and anterior extremities (2).

Sinnathambi et al. stated that the splenic statistics can be visualized in odd numbers; size measures 1 x 3 x 5 inches, weight $7 \mathrm{oz}$ (3). William's et al. described the adult spleen; usually about $12 \mathrm{~cm}$ long, $7 \mathrm{~cm}$ broad, $3-4 \mathrm{~cm}$ wide and weighs about $150 \mathrm{~g}$ (normal range $80-300 \mathrm{~g}$ ) (2). Embryologically spleen develops from the dorsal mesogastrium, initially as few splenic nodules, which subsequently fuse to form the spleen proper. As a result of rotation of the stomach, it takes the position of left hypochondrium

between two leaves of the dorsal mesogastrium $(4,5)$.

Spleen has both immunological and haematological functions, in which the white and red pulp serves important roles. Precisely, the white pulp stores B and T lymphocytes while the red pulp is an important site for extra medullary erythropoiesis acting as a blood filter for foreign material and damaged blood cells (4).

Spleen is frequently subjected to routine splenic surgeries and also a potential site of life threatening hemorrhages in trauma leading to emergency splenic explorations. Splenic surgeries vary from open total/ partial splenectomy to laparoscopic splenectomy, where the knowledge of splenic anatomy and surgical techniques are imperative for good results (5).

This organ is involved with a wide variety of congenital and acquired disease conditions, thus frequently been subjected to radiological assessments. Having a sound knowledge on detailed splenic morphology and morphometry is of value as it prevents misinterpreting normal splenic variations as pathologies.

Establishment of normative measurements, normal morphology and its variations is required to fulfill the above needs. The present preliminary study is aimed at evaluating the normal morphometry of the spleen in a Sri Lankan adult population and is fully justified due to scarcity of such information for this population.

\section{MATERIALS AND METHOD}

This cross sectional observational study was conducted in the department of 
KODIKARA S. K. Y. I., NANAYAKKARA B.C. I. J, NANAYAKKARA B. G., ILAYPERUMA I. Splenic Morphometry in a Group of Sri Lankan Adult Population-A Preliminary Cadaveric Study. Sri Lanka Anatomy Journal (SLAJ), 1(1): 44-52, 2017.

Anatomy, University of Ruhuna, from June 2016 to August 2016, using thirty $(\mathrm{n}=30)$, male and female cadaveric spleens (age range 20- 80 years). These cadavers were stored in $10 \%$ formalin filled tanks following embalming according to the standard procedure by injecting $10 \%$ formalin based preservative. Identification details and past medical history were available in record. Any cadaver with a history of haemopoetic or reticular endothelial disorder, ruptured or grossly adhered spleens were excluded from the study. Eight $(\mathrm{n}=08)$ spleens were excluded due to above reasons.

The external appearances of the spleens were observed and photographed using a13 mega pixel digital camera. Splenic shapes were recorded (semilunar, wedge, tetrahedral, polygonal wedge, single lobed liver shape). Location and number of splenic notches were recorded with regard to the superior or inferior border of the spleen (i.e. superior border separates the diaphragmatic surface from the gastric impression and inferior border separates the renal impression from the diaphragmatic surface) and with regards to the upper and lower poles (2). The morphology compatible with the standard textbook description was considered as the normal morphology (2)(3). Any abnormal morphology was recorded and photographed.

\section{Measurement procedures}

Maximum upper to lower pole length, breadth and thickness of the spleens were recorded in centimeters, using a Tricebrand Vernier caliper with accuracy up to $0.001 \mathrm{~cm}$. The weight was recorded using a manual three beam balance, with accuracy up to $0.1 \mathrm{~g}$. The splenic index was calculated; maximum length $\mathrm{x}$ width $\mathrm{x}$ thickness. The volume of spleen was calculated by using the standard clinical prolate ellipsoid equation for spleen [0.524 $\times$ splenic index] $(8,9)$.

Mean and the standard deviations of the splenic length, thickness, volume, and weight were calculated. The association between the splenic parameters (length and volume) was evaluated using Pearson correlation coefficient.

\section{RESULTS}

In the present study mean length, width, thickness and the weight of the spleen were $8.06 \pm 1.66 \mathrm{~cm}, 5.71 \pm 1.05 \mathrm{~cm}$ and $3.56 \pm 0.89 \mathrm{~cm}$ and $80.13 \pm 35.84 \mathrm{~g}$ respectively (Table 1). Out of the total spleens, thirteen $(43.3 \%)$ were semi lunar shape, ten $(33.3 \%)$ wedge, three (10\%) oval, one $(3.3 \%)$ tetrahedral shaped, two $(6.6 \%)$ polygonal wedge and one $(3.3 \%)$ was single lobed liver shaped (Figures 1 \&2). Notches were absent in five spleens (16.67\%). The notches were exclusively observed in the superior border. Single 
KODIKARA S. K. Y. I., NANAYAKKARA B.C. I. J, NANAYAKKARA B. G., ILAYPERUMA I. Splenic Morphometry in a Group of Sri Lankan Adult Population-A Preliminary Cadaveric Study. Sri Lanka Anatomy Journal (SLAJ), 1(1): 44-52, 2017.

notch was seen in eight spleens $(26.7 \%)$ and $30 \%$ were in upper pole (posterior extremity) notches. More than one notch was present in fourteen spleens $(46.7 \%)$ and $81.8 \%$ were in the upper pole.
Maximum number of splenic notches observed was four (Table 2). Mean splenic volume and splenic index were $91.52 \pm$ $45.67 \mathrm{~cm}^{3}$ and $174.67 \pm 87.17$ respectively.

Table 1: Mean length, width, thickness and weight and standard deviation of the spleens

\begin{tabular}{ccc}
\hline & Mean & Standard deviation \\
\hline Length & $8.06 \mathrm{~cm}$ & 1.66 \\
Width & $5.71 \mathrm{~cm}$ & 1.05 \\
Thickness & $3.56 \mathrm{~cm}$ & 0.89 \\
Weight & $80.13 \mathrm{~g}$ & 35.84 \\
\hline
\end{tabular}

Table 2: Number of splenic notches and their distribution in upper and lower poles

\begin{tabular}{cccc}
\hline Number of notches & Percentage & Location of notches & Percentage \\
\hline Absent & $16.6 \%$ & NA & NA \\
Single notch & $26.7 \%$ & Upper pole & $30 \%$ \\
& & Lower pole & $70 \%$ \\
More than one notch & $46.7 \%$ & Upper pole & $81.1 \%$ \\
& & Lower pole & $19.9 \%$ \\
\hline
\end{tabular}

(NA- Not applicable)

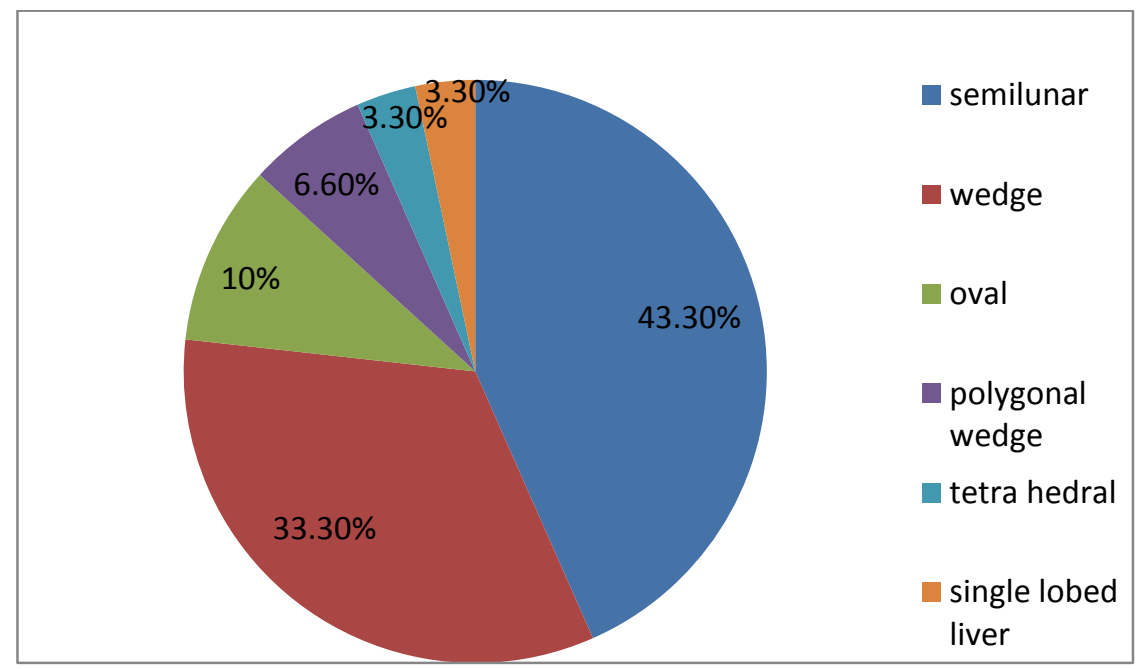

Figure 1. Splenic shapes 
KODIKARA S. K. Y. I., NANAYAKKARA B.C. I. J, NANAYAKKARA B. G., ILAYPERUMA I. Splenic Morphometry in a Group of Sri Lankan Adult Population-A Preliminary Cadaveric Study. Sri Lanka Anatomy Journal (SLAJ), 1(1): 44-52, 2017.

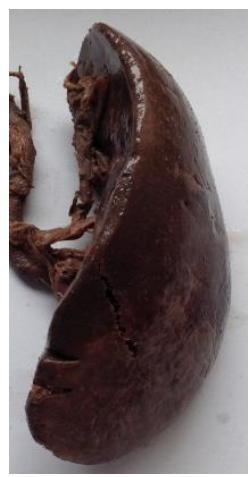

A. Semi lunar

Shape

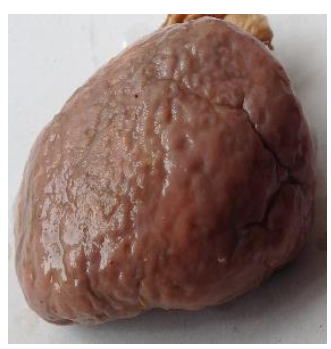

B. Oval shape

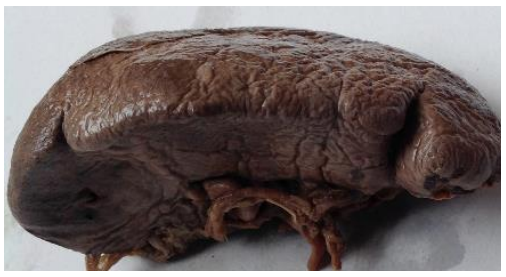

C. Wedge shape

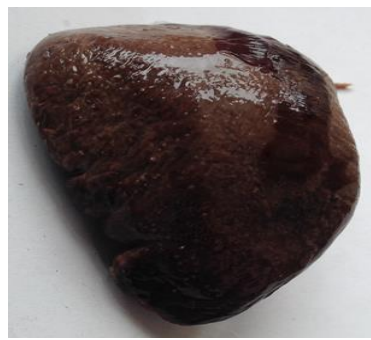

D. Liver shape

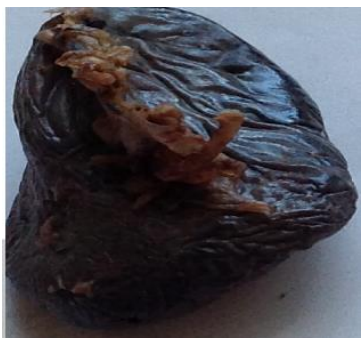

E. Polygonal wedge

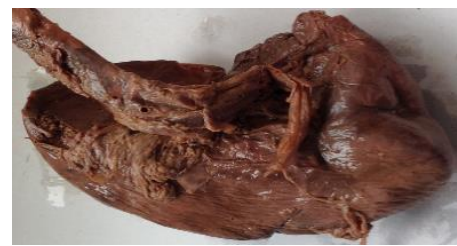

F. Tetrahedral shape

Figure 2 (A-F). Splenic shapes

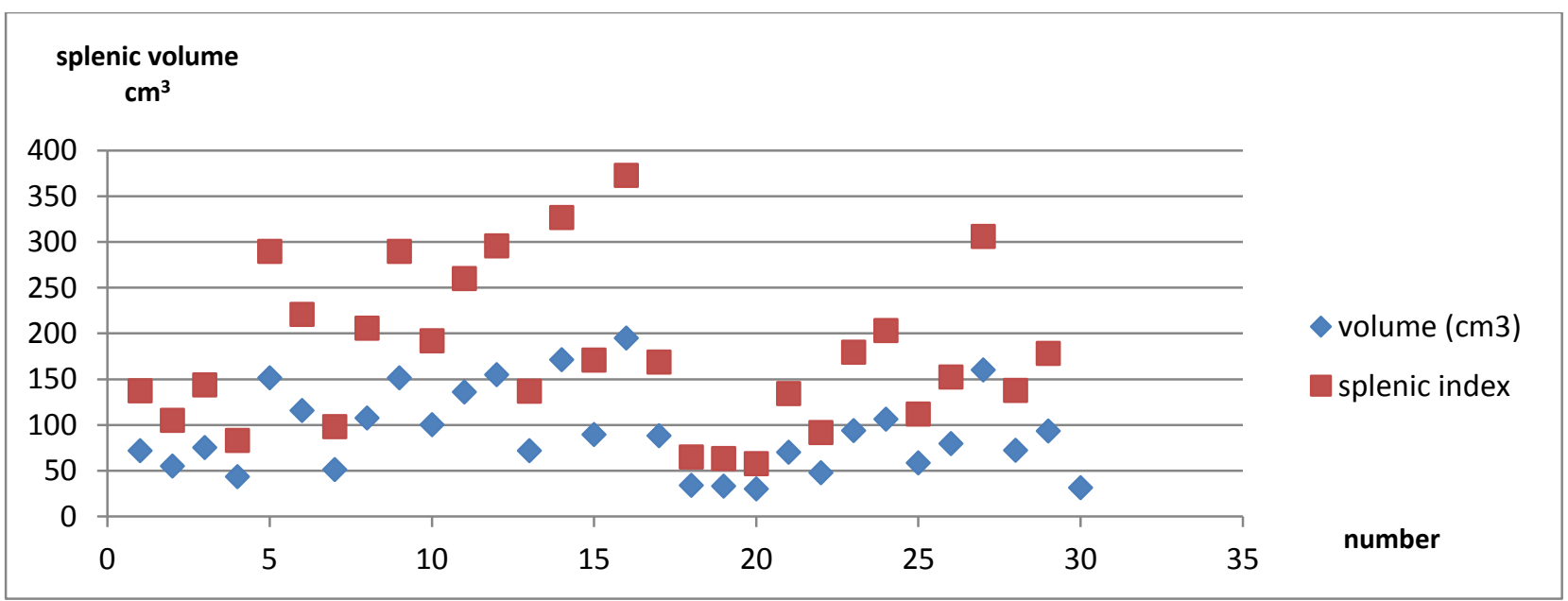

Figure 3. Distribution of the splenic volume and the index 
KODIKARA S. K. Y. I., NANAYAKKARA B.C. I. J, NANAYAKKARA B. G., ILAYPERUMA I. Splenic Morphometry in a Group of Sri Lankan Adult Population-A Preliminary Cadaveric Study. Sri Lanka Anatomy Journal (SLAJ), 1(1): 44-52, 2017.

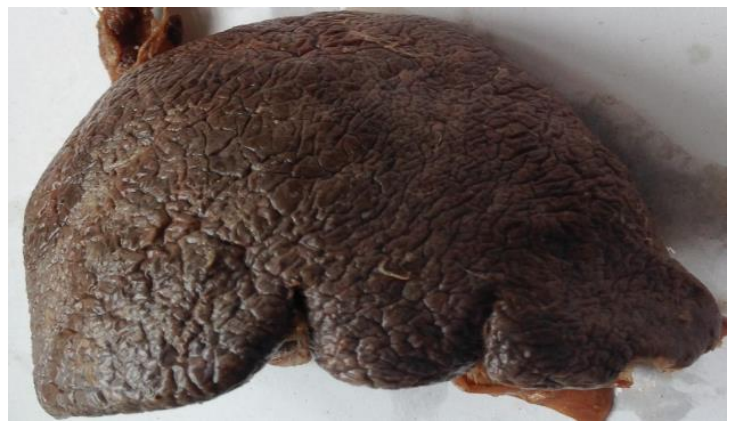

Figure 4. Splenic notches in superior surface of the spleen

A strong positive correlation was identified with the splenic length and the volume (r- 0.8393 and $\mathrm{r}^{2}-0.7044, \mathrm{P}<$ 0.00001, is significant at $\mathrm{p}<0.01$ ) (Fig: 5).
Splenic thickness was weakly but positively correlated to the splenic volume(r- 0.1947 and $\mathrm{r}^{2}-0.0379, \mathrm{P}<$ 0.29391) (Fig: 6). A moderately positive correlation was noted between splenic width and volume $\left(\mathrm{r}-0.7384, \mathrm{r}^{2}-0.5452\right.$ and $\left.\mathrm{P}<0.00001\right)$. A strong positive correlation was observed between the splenic volume and the weight $\left(r-0.9044, r^{2}-0.8179\right)$.

$\checkmark$ Splenic volume (ml)

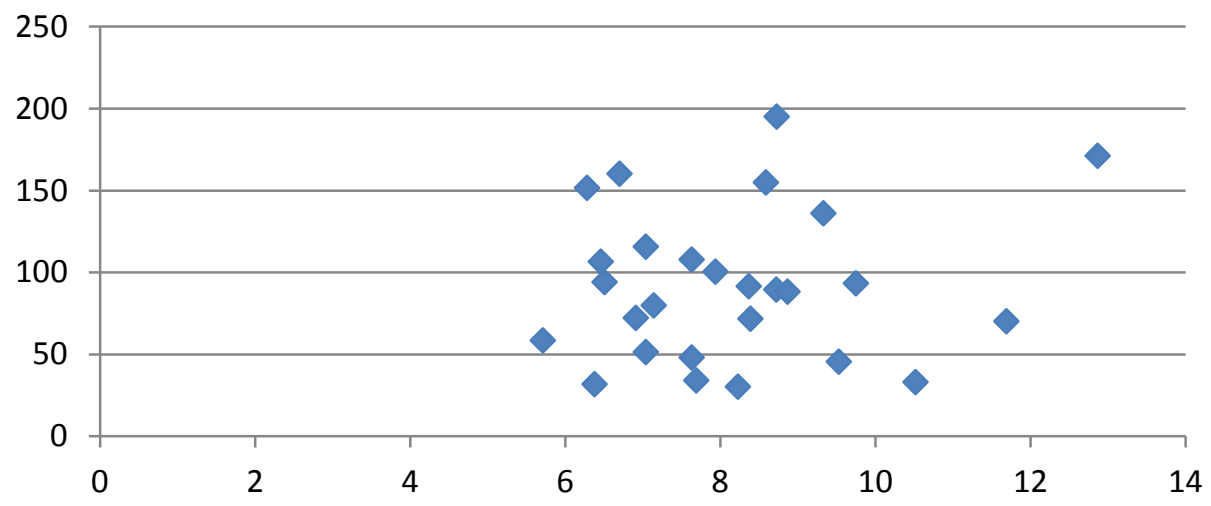

Figure 5. Correlation between splenic volume and splenic length 


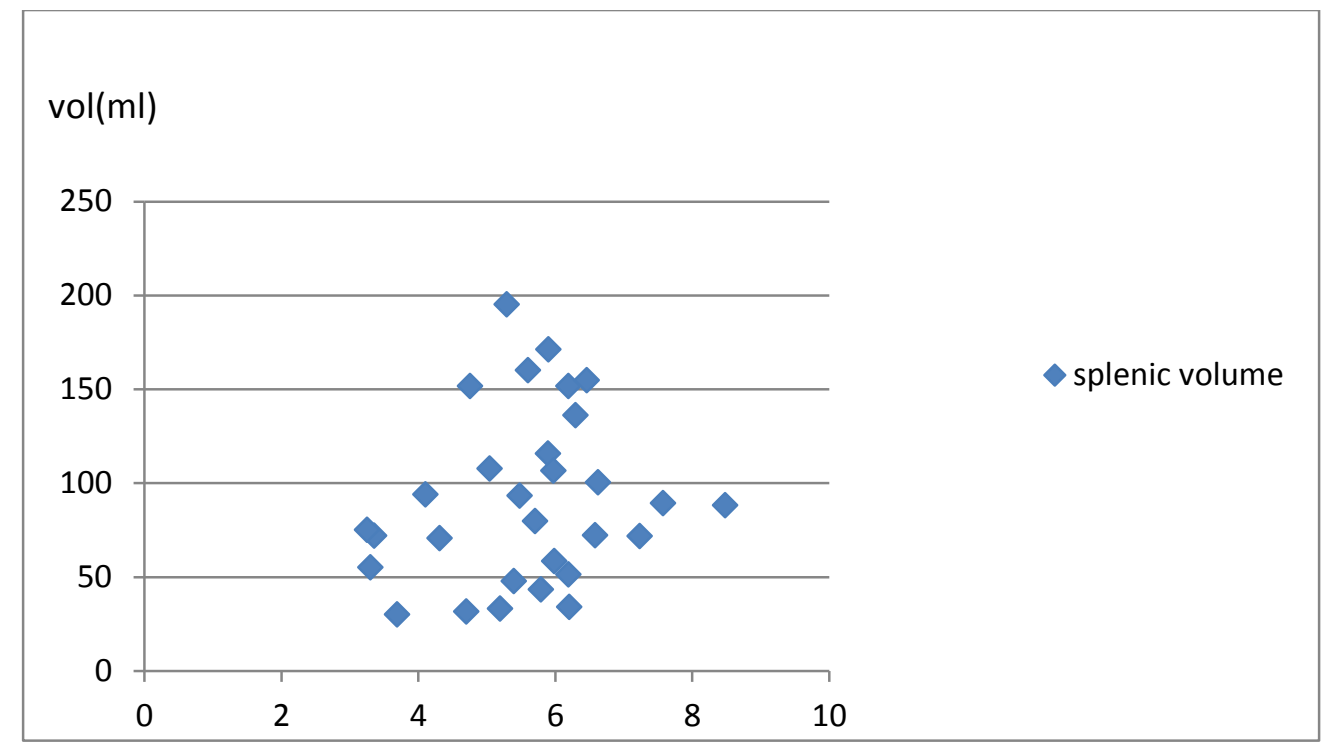

Figure 6. Correlation between the splenic volume and splenic thickness

\section{DISCUSSION}

Splenomegaly and small sized spleens are seen in a wide variety of clinical conditions. Palpation methods are widely used to diagnose splenomegaly. Napoli et al. stated, that precise estimation of the pre-operative splenic volume is important in laparoscopic splenectomy (6). The mean volume of the spleen in African adults is smaller than the available data from Western sources, which cannot be explained by differences in body habitus (7). Therefore, population specific data is important in clinical diagnosis of splenomegaly and to diagnose small contracted spleens. Present study provides valuable detailed splenic morphometric analysis for Sri Lankan adults.

The observations from the present study reconfirm wedge shape as the commonest shape $(12,13)$. In our study, the wedge shape was closely followed by semi lunar shape, which is not a commonly described shape in other populations.

Location of the splenic notch was compared with the other available data. Das et al. and Girish et al. (14,15) described $98 \%$ and $95 \%$, respectively of superior border notches in their studies, while we found $100 \%$ superior border notches. Therefore, Sri Lankan splenic morphology described in this study is compatible with other populations.

Though the mean splenic weight established was $80.13 \mathrm{~g} \pm 35.84 \mathrm{~g}$, a wide variation was noted in splenic weight among the study population (range 25.8 $151.5 \mathrm{~g})$. This wide variation was true for the splenic volume as well, mean 91.53 $\mathrm{cm}^{3} \pm 45.67$, range $30.24-195.23 \mathrm{~cm}^{3}$. 
KODIKARA S. K. Y. I., NANAYAKKARA B.C. I. J, NANAYAKKARA B. G., ILAYPERUMA I. Splenic Morphometry in a Group of Sri Lankan Adult Population-A Preliminary Cadaveric Study. Sri Lanka Anatomy Journal (SLAJ), 1(1): 44-52, 2017.

This type of wide variation has been observed in other populations as well (8), which can be due to variations in patient height. Adil Asghar et al. stated that there is a significant correlation between patient height, surface area and the splenic volume with $r=0.521, p<0.05(9)$. Therefore, it is highly recommended to establish normative measurements of the spleen, not only for the age but also for the height as well.

A strong positive relationship was established with splenic length vs. splenic volume and with splenic weight vs. volume. A moderate positive correlation was established with splenic width vs. Splenic volume. Therefore, ultra-sound scan time can be markedly reduced by measuring only bipolar splenic length, which is technically fast and accurate compared to the measurement of the splenic width and the thickness. Width of the spleen can be measured in borderline cases to confirm splenomegaly.

\section{LIMITATIONS}

Main limitation of this study is the small sample size, which directly affects the generalization of our estimation. Additionally, this study was done with formalin preserved cadaveric spleen, without giving allowances for the shrinkage. To overcome these problems, it is recommended to use large unpreserved samples to establish population specific morphometry of the spleen.

\section{CONCLUSION}

In real time ultra sound scan evaluation of the splenic size, it is time saving to measure only the bipolar length to predict the true volume and weight. Splenic width can be taken into consideration when findings are marginal or inconclusive.

Population specific splenic measurements should be established using a large sample according to the age as well as the height.

\section{REFERENCES}

1. Snell RS. Clinical Anatomy by regions. Lippincott Williams \& Wilkins, 2013.

2. William's et.al, $8^{\text {th }}$ edition. Gray's anatomy.

3. Sinnathamby CS. Last's Anatomy. Elsevier, 2011.

4. de Porto AP NA, Lammers AJJ, Bennink RJ, et.al. Assessment of splenic functions. Eur J Clin Microbiol Infect Dis, 2010, 29: 1465-1473.

5. Panagiotis N, Skandalakis, et.al, Surgical Anatomy of the spleen. Surgical Anatomy and embryology: 747-768.

6. Napoli A, Catalano C, Silecchia G et al. Laparoscopic splenectomy: multidetector row CT for preoperative evaluation. 2004, Radiology; 232: 361-367.

7. Mustapha Z, Tahir A, Tukur M, Bukar M, Lee WK. Sonographic determination of normal spleen size in an adult African population. 2010, Eur J Radiol; 75:864872.

8. Siddiqui MA, Hassan AA, Bedewi MA.et. al. Estimation of standard splenic volume in Saudi Arabian adult population: Using 3D reconstruction of abdominal CT scans. 2014, Open Journal of Internal Medicine: 421-425.

9. AdilAsghar D, Agrawal SM, Yunus et al.Standard splenic volume estimation in North Indian adult population: Using 3D 
KODIKARA S. K. Y. I., NANAYAKKARA B.C. I. J, NANAYAKKARA B. G., ILAYPERUMA I. Splenic Morphometry in a Group of Sri Lankan Adult Population-A Preliminary Cadaveric Study. Sri Lanka Anatomy Journal (SLAJ), 1(1): 44-52, 2017.

reconstruction of abdominal CT scan images. 2011, Anatomy Research International;332-333.

10. T.W.Sadler. Digestive system. Langman's Medical Embryology. 2010.

11. Chaware PN, Belsare SM, Kulkarni YR. Morphological variations of the human spleen. 2013, Int J Bio Med Res; 4: 34648.

12. Das S, Latiff ABD et al. Anomalous splenic notches: A cadaveric study with clinical importance. 2008: 232-241.

13. Study of splenic notches in a human cadaver. Garish VP, Shishikumar et al.
2014, International Journal in Recent Advances in Multidiciplinary Research, 66-72.

14. Pansky B. The Foregut: The Pancreas and Spleen. Review of Medical Embryology.

15. Estimating splenic volume. Ellen MY, Katrina BA, Mary C, Olson et.al. 2003, American Journal of Radiology, 181:1615-1620.

16. Hollinshed WH, Anatomy for surgeons. 1982: 877-885.

\section{CORRESPONDENCE:}

Dr. S. K. Y. I. Kodikara,

Department of Anatomy,

University of Ruhuna,

E-mail-iroshani.kodikara@gmail.com

Received: July 2017

Accepted: August 2017 